\title{
$\angle S$ Research Square \\ The Association between BMI, Smoking, Drinking and Thyroid Disease: A Cross-sectional Study in Wuhan, China
}

\section{Xiao Chen}

Department of Endocrinology, Union Hospital, Tongji Medical College, Huazhong University of Science and Technology, Wuhan

\section{Juanjuan Wang}

Department of Endocrinology, The Central Hospital of Wuhan, Wuhan

\section{Li Yu}

Department of Emergency, Union Hospital, Tongji Medical College, Huazhong University of Science and Technology, Wuhan

\section{Hanyu Wang}

Department of Endocrinology, Union Hospital, Tongji Medical College, Huazhong University of Science and Technology, Wuhan

Hui Sun ( $\square$ sunny68@hust.edu.cn )

Department of Endocrinology, Union Hospital, Tongji Medical College, Huazhong University of Science and Technology, Wuhan

\section{Research Article}

Keywords: hypothyroidism, thyroid nodules, BMI, smoking, drinking, obesity

Posted Date: January 18th, 2021

DOl: https://doi.org/10.21203/rs.3.rs-144518/v1

License: @ (i) This work is licensed under a Creative Commons Attribution 4.0 International License.

Read Full License 


\section{Abstract}

Background: There is no clear conclusion on the relationship between thyroid disease and obesity and living habits such as smoking and drinking. In this study, a cross-sectional survey of urban residents in central China was conducted to analyze the association of body mass index (BMI), smoking and drinking with subclinical hypothyroidism (SHO) and thyroid nodules (TNs), and to discuss the potential mechanism between these risk or protective factors and the two diseases.

Methods: This study included 1279 participants in 2011 and 2012. Questionnaire survey, laboratory examination and ultrasonic diagnosis were conducted on these participants. Binary logistics regression analysis was used to analyze these factors.

Results: Overweight (BMI $\geq 25 \mathrm{~kg} / \mathrm{m}^{2}$ ) was closely related to subclinical hypothyroidism and thyroid nodules in univariate and multivariate logistics regression analysis. Smoking had protective effect on subclinical hypothyroidism and thyroid nodules in univariate logistics regression, while drinking had protective effect on thyroid nodules in univariate logistics regression, but there was no significant difference between smoking and drinking and two kinds of thyroid diseases in multivariate logistics regression analysis. In subgroup analysis, $\mathrm{BMI} \geq 25 \mathrm{~kg} / \mathrm{m} 2$ was significantly associated with subclinical hypothyroidism in people with positive thyroid antibodies $(\mathrm{OR}=2.221,95 \% \mathrm{Cl}: 1.168-4.184, \mathrm{P}=0.015)$ and smokers $(\mathrm{OR}=2.179,95 \% \mathrm{Cl}: 1.041-4.561, \mathrm{P}=0.039)$. Thyroid nodules were significantly associated with thyroid nodules in people over 60 years old $(\mathrm{OR}=2.069,95 \% \mathrm{Cl}: 1.149-3.724, \mathrm{P}=0.015)$ and drinkers $(\mathrm{OR}=3.065,95 \% \mathrm{Cl}: 1.413-6.648, \mathrm{P}=0.005)$. Drinking alcohol has a protective effect on thyroid nodules in smokers $(\mathrm{OR}=0.456,95 \% \mathrm{Cl}: 0.240-0.865, \mathrm{P}=0.016)$ and people with $\mathrm{BMI} \geq 25 \mathrm{~kg} / \mathrm{m}^{2}(\mathrm{OR}=0.467,95 \% \mathrm{Cl}$ : $0.236-0.925, \mathrm{P}=0.029)$. No statistical association was found between smoking and the two thyroid diseases in different subgroups.

Conclusion: Obesity is a risk factor for thyroid disease, especially in the elderly and people with positive thyroid autoantibodies. Obesity and metabolic syndrome may be more associated with thyroid nodules than subclinical hypothyroidism. Smoking may be a protective factor for thyroid disease, while drinking is a protective factor for thyroid nodules.

\section{Background}

At present, thyroid nodules (TNs) and subclinical hypothyroidism (SHO) are two thyroid diseases which are very common around the world. Studies have reported that the prevalence of subclinical hypothyroidism is to be $4-20 \%[1]$. Besides, with the improvement of the level of imaging diagnosis, the prevalence of thyroid nodules have increased in recent years[2]. Because of the occult symptoms, these two thyroid diseases are often ignored by most patients, and the detection of the disease mainly depends on screening in the general population. However, a number of studies have shown that subclinical hypothyroidism is associated with increased risk of a variety of cardiovascular diseases[3] and cognitive impairment[4], and may develop into dominant hypothyroidism, and solitary thyroid nodules also have 
varying degrees of risk of deterioration[5]. Therefore, it is of great significance for the early diagnosis and early warning of the above two diseases, especially in the susceptible population with different risk factors.

There have been different studies on the risk factors related to subclinical hypothyroidism and thyroid nodules, among which sex and age are known factors that lead to an increased risk of thyroid disease [68], Hashimoto's thyroiditis also increases the risk. However, there is no clear conclusion on adverse metabolic conditions such as obesity, and living habits such as smoking and drinking. Although some studies have found that metabolic syndrome and obesity can lead to an increased risk of thyroid disease [9-11], However, this conclusion may have different manifestations in people with different characteristics, such as patients with autoimmune thyroid diseases, different ages and genders, and there are no studies on subclinical hypothyroidism and thyroid nodules at the same time. Considering that there may be some differences and connections in the pathogenesis of the two thyroid diseases, the same risk factors may have different effects on the two diseases. Therefore, by further evaluating the correlation between obesity and lifestyle and the two diseases in the subgroup, we can eliminate the influence of a variety of confounding factors to a certain extent, which is helpful to reveal the pathological mechanism of obesity, smoking and drinking on thyroid gland. And for people with varying degrees of risk of the disease, it may be more accurate to guide the way of thyroid examination and early intervention.

In our study, thyroid function and thyroid ultrasound examination were performed on 1500 randomly screened healthy residents in Wuhan, China. The effects of obesity, smoking and drinking on the prevalence of subclinical hypothyroidism and thyroid nodules were evaluated. After adjusting the related confounding factors through subgroup analysis, we further compared whether these factors would play a more significant role in thyroid disease in people with specific demographic characteristics.

\section{Methods}

\section{Study participants}

The study, conducted in a community in Wuhan, China, recruited a total of 1500 healthy residents in 2011 and 2012.All subjects gave their informed consent for inclusion before they participated in the study. The study was conducted in accordance with the Declaration of Helsinki, and the protocol was approved by the Ethics Committee of medical ethics committee of China Medical University (Serial number: IRB[2008]34). The inclusion criteria were as follows: 1) over the age of 20 years, 2) Han nationality, 3) living in Wuhan for at least 10 years, 4) did not receive iodine-containing contrast agent or drugs such as amiodarone within the past three months, and 5) no previous thyroid disease. We excluded subjects with clinically abnormal thyroid function, missing important information as well as pregnant and lactating women. After screening participants who met the study criteria, participants were divided into subclinical hypothyroidism group ( $\mathrm{N}=194)$ and non-subclinical hypothyroidism group $(\mathrm{N}=1085)$, thyroid nodule group ( $\mathrm{N}=238)$ and non-thyroid nodule group $(\mathrm{N}=1041)$ according to the diagnostic criteria. 


\section{Data Collection}

A standard questionnaire was designed to acquire basic information on participants, including name, gender, ethnicity, history of smoking and alcoholism,eating habits, medication history, female reproductive history, and family and personal history of thyroid disorders. According to the results of the questionnaire, laboratory and ultrasonic examinations were carried out on all the subjects who met the research criteria. Spot-urine and blood samples were collected in the morning after overnight fasting. UIC was determined by the ammonium persulfate method based on the Sandell-Kolthoff reaction (T6 UV spectrophotometry). Concentrations of serum thyroid-stimulating hormone (TSH), free triiodothyronine (FT3), free tetraiodothyronine (FT4), thyroperoxidase antibody (TPOAb), and thyroglobulin antibody (TgAb) were determined by electrochemiluminescent immunoassay (Roche Kit, Cobas-e601 analyzer). Thyroid ultrasonography was performed by professional physicians using a 7.5-MHz transducer (GE, LOGIQ a100). The normal reference values were as follows: FT4 12.0-22.0pmol/I, FT3 3.1-6.8pmol/I, TSH 0.27-4.2mU/L, TPOAb 0-34 IU/ml, and TgAb 0-115 IU/ml. Participants were also examined in terms of height (measured to the nearest $0.1 \mathrm{~cm}$ ) and weight (measured to the nearest $0.1 \mathrm{~kg}$ ) with the individuals wearing light clothes without shoes. Their diastolic blood pressure (DBP) and systolic blood pressure (SBP) (measured to nearest $1 \mathrm{mmHg}$ ) were measured using an electronics phygmomanometer (HBP9020, Omron, Japan) when the individuals were seated and quiet, taking two measurements with a separation of $30 \mathrm{~s}$ between each measurement, averaging the results[12].

\section{Definition of variables}

In this study, the definition of thyroid nodules is based on American Thyroid Association guidelines[13]囚 TNs was defined as a small lesion differentiated from the rest of the thyroid parenchyma, possessing a solid part, with or without the presence of a cystic part. Subclinical hypothyroidism is defined as serum FT3 and FT4 within the normal range but TSH exceeding 4.2mU/L. TPOAb positive was defined as serum TPOAb of more than $34 \mathrm{IU} / \mathrm{L}, \mathrm{TgAb}$ positive defined as serum TgAb of more than 115IU/L. The BMI index adopts the standard of $\mathrm{WHO}[14] \rrbracket$ the weight was divided by the square of height, and the result more than $25 \mathrm{~kg} / \mathrm{m}^{2}$ was defined as overweight. Smokers include people who currently smoke or have ever smoked, and the definition of drinkers is similar to that of smokers, including people who are or have had drinking habits. The specific number or types of smoking and drinking were not accurately investigated in this study.

\section{Statistical analysis}

All statistical analyses were conducted with SPSS software (IBM, Armonk, NY, USA, version 26.0). The Kolmogorov-Smirnov test was used to test normality. Normally distributed data were expressed with the mean \pm SD and abnormally distributed data were expressed with the median and interquartile range. The $t$ test was used to compare normal and continuous variables, the nonparametric rank test (Kruskal-Wallis) 
for non-normal and continuous variables, and the chi-square test to compare the prevalence of thyroid disorders between different groups. Odd ratios (ORs) and 95\% confidence intervals ( $95 \% \mathrm{Cls}$ ) were calculated using binary logistic regression analyses, Univariate logistics regression analysis and multivariate logistics regression analysis were used to evaluate the relationship between risk factors and subclinical hypothyroidism and thyroid nodules. Multivariate logistics regression was used to analyze the association between BMI and smoking, alcohol and disease in subgroup analysis. Considering the small sample size, the correlation analysis only included the indicators with significant statistical significance in the difference analysis. Differences in blood pressure and waistline were also not included in the correlation analysis, considering that they might be associated with obesity. A two-sided $\mathrm{P}<0.05$ was considered significant.

\section{Results}

\section{Baseline characteristics}

After excluding individuals who did not meet the study criteria and omitted information such as thyroid function, BMI and other key indicators, a total of 1279 of the 1500 participants were included in the study. There were 194 patients with subclinical hypothyroidism and 238 patients with thyroid nodules. These patients were compared with 1045 patients with non-subclinical hypothyroidism and 1081 patients with non-thyroid nodules (Fig. 1). In Table 1 and Table 2, the baseline data of the corresponding population of the two diseases and their respective control groups were analyzed. A total of 487 people were overweight, of which $18.1 \%$ were subclinical hypothyroidism (88/487) and $22.8 \%$ were thyroid nodules (111/487). 792 people were not overweight, of whom $13.4 \%$ were subclinical hypothyroidism $(106 / 792)$ and $16.0 \%$ were thyroid nodules (127/792). The prevalence of subclinical hypothyroidism $(18.1 \% \mathrm{vs}$ $13.4 \%, P=0.023)$ and thyroid nodules $(22.8 \%$ vs $16.0 \%, P=0.003)$ was significantly higher in overweight people than that in non-overweight people. There were 377 smokers, of whom $10.1 \%$ were subclinical hypothyroidism (38/377), and 15.1\% were thyroid nodules (57/377) $\square$ There were 902 non-smokers, 17.3\% were subclinical hypothyroidism $(156 / 902) \otimes 20.1 \%(181 / 902)$ were thyroid nodules $\square$ the prevalence of subclinical hypothyroidism ( $10.1 \%$ vs $17.3 \%, P=0.001)$ and thyroid nodules $(15.1 \%$ vs $20.1 \%, P=0.038)$ is lower than that in non-smokers. There were 256 drinkers and 1023 non-drinkers, the prevalence of thyroid nodules was $14.4 \%(36 / 256)$ in drinkers and $19.7 \%(202 / 1023)$ in non-drinkers $\square$ the prevalence of thyroid nodules in the former was lower than that in the latter( $14.1 \%$ vs $19.7 \%, P=0.037)$. The prevalence of SHO $(19.6 \%$ vs $8.8 \%, P=0.000)$ and $T N s(21.2 \%$ vs $14.9 \%, P=0.004)$ in females was significantly higher than that of males. The average age of patients with subclinical hypothyroidism and thyroid nodules was higher than that of non-subclinical hypothyroidism ( $47.25 \pm 14.99$ vs $44.57 \pm 14.54, P=0.000)$ and nonthyroid nodules $(52.84 \pm 14.65$ vs $43.17 \pm 14.43$ years, $P=0.000)$. People with positive thyroid autoantibodies (beyond the normal reference range) had a higher prevalence of subclinical hypothyroidism than those with negative thyroid autoantibodies, including TPOAb positive patients ( $26.2 \%$ vs $13.8 \%, P=0.000)$ and $\operatorname{TgAb}$ positive patients $(29.8 \%$ vs $13.2 \%, \mathrm{P}=0.000)$. The average $\mathrm{SBP}(120.54 \pm 20.01$ vs $113.93 \pm 19.83 \mathrm{mmHg}, \mathrm{P}=0.000), \mathrm{DBP}(77.15 \pm 11.35$ vs $75.09 \pm 11.9 \mathrm{mmHg}, \mathrm{P}=$ 
$0.015)$ and the median waist circumference ( $84 \mathrm{vs} 82 \mathrm{~cm}, \mathrm{P}=0.000$ ) of patients with thyroid nodules were higher than those of patients with non-thyroid nodules. 
Table 1

Baseline characteristics of the participants with or without subclinical hypothyroidism

\begin{tabular}{|c|c|c|c|}
\hline Characteristics & $\mathrm{SHO}(\mathrm{N}=194)$ & No $\mathrm{SHO}(\mathrm{N}=1085)$ & $P$ value \\
\hline Gender(n,\%) & & & 0.000 \\
\hline Male & $46(8.8 \%)$ & $478(91.2 \%)$ & \\
\hline Female & $148(19.6 \%)$ & $607(80.4 \%)$ & \\
\hline Age(years) & $47.25 \pm 14.99$ & $44.57 \pm 14.54$ & 0.021 \\
\hline Waistlin, median(IQR), cm & $84(76-90)$ & $82(74-88)$ & 0.098 \\
\hline $\mathrm{SBP}(\mathrm{mmHg})$ & $117.33 \pm 20.52$ & $114.78 \pm 20.14$ & 0.105 \\
\hline $\mathrm{DBP}(\mathrm{mmHg})$ & $76.41 \pm 11.30$ & $75.30 \pm 11.91$ & 0.229 \\
\hline TPOAb, n(\%), IU/L & & & 0.000 \\
\hline$>34$ & $38(26.2 \%)$ & 107(73.8\%) & \\
\hline$\leq 34$ & $156(13.8 \%)$ & $978(86.2 \%)$ & \\
\hline $\operatorname{TgAb}, \mathrm{n}(\%), \mathrm{IU} / \mathrm{L}$ & & & 0.000 \\
\hline$>115$ & $45(29.8 \%)$ & 106(70.2\%) & \\
\hline$\leq 115$ & $149(13.2 \%)$ & $979(86.8 \%)$ & \\
\hline Smoker(n,\%) & & & 0.001 \\
\hline Yes & $38(10.1 \%)($ & $339(89.9 \%)$ & \\
\hline No & 156(17.3\%) & 746(82.7\%) & \\
\hline Drinker(n,\%) & & & 0.127 \\
\hline Yes & $31(12.1 \%)$ & $225(87.9 \%)$ & \\
\hline No & $163(15.9 \%)$ & $860(84.1 \%)$ & \\
\hline Fatty liver(n,\%) & & & 0.052 \\
\hline Yes & $60(18.5 \%)$ & $264(81.5 \%)$ & \\
\hline No & $134(14.0 \%)$ & $821(86.0 \%)$ & \\
\hline $\mathrm{BMI}, \mathrm{n}(\%), \mathrm{kg} / \mathrm{m}^{2}$ & & & 0.023 \\
\hline$\geq 25$ & $88(18.1 \%)$ & $399(81.9 \%)$ & \\
\hline$<25$ & 106(13.4\%) & $686(86.6 \%)$ & \\
\hline
\end{tabular}




\begin{tabular}{|c|c|c|c|}
\hline Characteristics & $\mathrm{SHO}(\mathrm{N}=194)$ & No $\mathrm{SHO}(\mathrm{N}=1085)$ & $P$ value \\
\hline Urine iodine, median(IQR), $\mu \mathrm{g} / \mathrm{L}$ & $210(151-298)$ & $222(154-305)$ & 0.718 \\
\hline \multicolumn{3}{|l|}{ Urine iodine, $n(\%), \mu g / L$} & 0.737 \\
\hline$\leq 200$ & $84(15.6 \%)$ & $453(84.4 \%)$ & \\
\hline $200-300$ & $63(15.6 \%)$ & $340(84.4 \%)$ & \\
\hline$>300$ & $47(13.9 \%)$ & $292(86.1 \%)$ & \\
\hline \multicolumn{4}{|c|}{$\begin{array}{l}\text { Abbreviations: SHO subclinical hypothyroidism, N number, IQR interquartile range, BMI body mass } \\
\text { index, SBP systolic blood pressure, DBP diastolic blood pressure, TPOAb thyroid peroxidase antibody, } \\
\text { TgAb thyroglobulin antibody }\end{array}$} \\
\hline
\end{tabular}


Table 2

Baseline characteristics of the participants with or without thyroid nodules

\begin{tabular}{|c|c|c|c|}
\hline Characteristics & $\mathrm{TNs}(\mathrm{N}=238)$ & No TNs(n = 1041) & $P$ value \\
\hline Gender(n,\%) & & & 0.004 \\
\hline Male & $78(14.9 \%)$ & $446(85.1 \%)$ & \\
\hline Female & $160(21.2 \%)$ & $595(78.8 \%)$ & \\
\hline Age(years) & $52.84 \pm 14.65$ & $43.17 \pm 14.43$ & 0.000 \\
\hline Waistlin, median(IQR), cm & $84(77-92)$ & $82(74-88)$ & 0.000 \\
\hline $\mathrm{SBP}(\mathrm{mmHg})$ & $120.54 \pm 20.01$ & $113.93 \pm 19.83$ & 0.000 \\
\hline $\mathrm{DBP}(\mathrm{mmHg})$ & $77.15 \pm 11.35$ & $75.09 \pm 11.91$ & 0.015 \\
\hline TPOAb, n(\%), IU/L & & & 0.647 \\
\hline$>34$ & $29(20.0 \%)$ & $116(80.0 \%)$ & \\
\hline$\leq 34$ & $209(18.4 \%)$ & $925(81.6 \%)$ & \\
\hline $\operatorname{TgAb}, \mathrm{n}(\%), \mathrm{IU} / \mathrm{L}$ & & & 0.982 \\
\hline$>115$ & $28(18.5 \%)$ & $123(81.5 \%)$ & \\
\hline$\leq 115$ & $210(18.6 \%)$ & $918(81.4 \%)$ & \\
\hline $\mathrm{TSH}$, median(IQR), mU/L & $2.59(1.78-3.53)$ & $2.51(1.79-3.62)$ & 0.974 \\
\hline Smoker(n,\%) & & & 0.038 \\
\hline Yes & $57(15.1 \%)$ & $320(84.9 \%)$ & \\
\hline No & 181(20.1\%) & $721(79.9 \%)$ & \\
\hline Drinker(n,\%) & & & 0.037 \\
\hline Yes & $36(14.1 \%)$ & $220(85.9 \%)$ & \\
\hline No & 202(19.7\%) & $821(80.3 \%)$ & \\
\hline Fatty liver(n,\%) & & & 0.053 \\
\hline Yes & $72(22.2 \%)$ & $252(77.8 \%)$ & \\
\hline No & 166(17.4\%) & $789(82.6 \%)$ & \\
\hline BMI, n(\%),kg/m² & & & 0.003 \\
\hline
\end{tabular}

Abbreviations: TNs thyroid nodules, N number, IQR interquartile range, BMI body mass index, SBP systolic blood pressure, DBP diastolic blood pressure, TPOAb thyroid peroxidase antibody, TgAb thyroglobulin antibody, TSH thyroid-stimulating hormone 


\begin{tabular}{|llll|}
\hline Characteristics & TNs(N= 238) & No TNs( $\mathbf{n = 1 0 4 1 )}$ & P value \\
\hline$\geq 25$ & $111(22.8 \%)$ & $376(77.2 \%)$ & \\
\hline$<25$ & $127(16.0 \%)$ & $665(84.0 \%)$ & 0.557 \\
\hline Urine iodine, median(IQR), $\mathrm{gg} / \mathrm{L}$ & $224(150-331)$ & $219(154-303)$ & 0.783 \\
\hline Urine iodine ,n(\%), $\mathrm{gg} / \mathrm{L}$ & & & \\
$\leq 200$ & $96(17.9 \%)$ & $441(82.1 \%)$ & \\
\hline $200-300$ & $75(18.6 \%)$ & $328(81.4 \%)$ & \\
\hline$>300$ & $67(19.8 \%)$ & $272(80.2 \%)$ & \\
\hline $\begin{array}{l}\text { Abbreviations: TNs thyroid nodules, N number, IQR interquartile range, BMI body mass index, SBP } \\
\text { systolic blood pressure, DBP diastolic blood pressure, TPOAb thyroid peroxidase antibody, TgAb } \\
\text { thyroglobulin antibody, TSH thyroid-stimulating hormone }\end{array}$ & & \\
\hline
\end{tabular}

\section{The associate between different risk factors and two thyroid diseases}

Table 3 and Table 4 further demonstrated the statistically significant association between different risk or protective factors and thyroid disease in the difference analysis. After adjusting other covariates, multivariate logistics regression analysis showed that age, female and overweight (BMI $\geq 25 \mathrm{~kg} / \mathrm{m} 2$ ) were closely related to the two thyroid diseases, and thyroid antibody positive was closely related to subclinical hypothyroidism. After further treatment of age as a classification variable, people in the 4060 age group had the highest risk of subclinical hypothyroidism $(\mathrm{OR}=1.497,95 \% \mathrm{Cl}: 1.052-2.129, \mathrm{P}=$ $0.025)$,people older than 60 years old have the highest risk of thyroid nodules (OR $=4.459,95 \% \mathrm{Cl}: 2.973-$ $6.687, \mathrm{P}=0.000$ ). Among patients with positive thyroid antibodies, patients with single positive TPOAb had the highest risk of subclinical hypothyroidism $(\mathrm{OR}=2.329,95 \% \mathrm{Cl}: 1.345-4.032, \mathrm{P}=0.003)$. In univariate logistics regression analysis, smoking had protective effects on thyroid nodules $(O R=0.710$, $95 \% \mathrm{Cl}: 0.512-0.983, \mathrm{P}=0.039)$ and subclinical hypothyroidism(OR $=0.53695 \% \mathrm{Cl}: 0.368-0.782, \mathrm{P}=$ $0.001)$, Drinking has a protective effect on thyroid nodules( $\mathrm{OR}=0.665,95 \% \mathrm{Cl}: 0.453-0.977, \mathrm{P}=0.038)$. However, in multivariate logistics regression analysis, the protective effects of smoking and alcohol consumption were statistically eliminated. 
Table 3

The association between different risk/protect factors with subclinical hypothyroidism

\begin{tabular}{|c|c|c|c|c|c|c|}
\hline \multirow[t]{2}{*}{ Characteristics } & \multicolumn{3}{|c|}{ Univariate logistic regression } & \multicolumn{3}{|c|}{ Multivariate logistic regression } \\
\hline & OR & $95 \% \mathrm{Cl}$ & $P$ value & OR & $95 \% \mathrm{Cl}$ & $P$ value \\
\hline \multicolumn{7}{|l|}{ Age(years) } \\
\hline$\leq 40$ & \multicolumn{3}{|c|}{ reference } & \multicolumn{3}{|c|}{ reference } \\
\hline $40-60$ & 1.664 & $1.183-2.340$ & 0.003 & 1.497 & $1.052-2.129$ & 0.025 \\
\hline$>60$ & 1.368 & $0.875-2.140$ & 0.170 & 1.194 & $0.748-1.907$ & 0.458 \\
\hline \multicolumn{7}{|l|}{ Gender } \\
\hline Male & \multicolumn{3}{|c|}{ reference } & \multicolumn{3}{|c|}{ reference } \\
\hline Female & 2.534 & $1.782-3.602$ & 0.000 & 2.398 & $1.471-3.909$ & 0.000 \\
\hline \multicolumn{7}{|l|}{ Antibody } \\
\hline TPOAb-/TgAb- & \multicolumn{3}{|c|}{ reference } & \multicolumn{3}{|c|}{ reference } \\
\hline TPOAb+/TgAb- & 3.047 & $1.788-5.193$ & 0.000 & 2.329 & $1.345-4.032$ & 0.003 \\
\hline TPOAb-/TgAb+ & 2.037 & $1.114-3.724$ & 0.021 & 2.002 & $1.081-3.707$ & 0.027 \\
\hline TPOAb+/TgAb+ & 2.844 & $1.694-4.775$ & 0.000 & 2.154 & $1.263-3.676$ & 0.005 \\
\hline \multicolumn{7}{|l|}{ Smoker } \\
\hline No & \multicolumn{3}{|c|}{ reference } & \multicolumn{3}{|c|}{ reference } \\
\hline Yes & 0.536 & $0.368-0.782$ & 0.001 & 1.002 & $0.596-1.685$ & 0.993 \\
\hline \multicolumn{7}{|l|}{$\operatorname{BMI}\left(\mathrm{kg} / \mathrm{m}^{2}\right)$} \\
\hline$<25$ & \multicolumn{3}{|c|}{ reference } & \multicolumn{3}{|c|}{ reference } \\
\hline$\geq 25$ & 1.427 & $1.049-1.943$ & 0.024 & 1.581 & $1.137-2.199$ & 0.006 \\
\hline \multicolumn{7}{|c|}{$\begin{array}{l}\text { Abbreviations: TPOAb-/TgAb- thyroid peroxidase antibody and thyroglobulin antibody are both } \\
\text { negative, TPOAb+/TgAb-thyroid peroxidase antibody is positive and thyroglobulin antibody is } \\
\text { negative, TPOAb-/TgAb + thyroid peroxidase antibody is negative and thyroglobulin antibody is } \\
\text { positive, TPOAb+/TgAb + thyroid peroxidase antibody and thyroglobulin antibody are both positive, } \\
\text { BMl body mass index. The Covariant included in multivariate logistic regression are age, gender, } \\
\text { antibody, smoker and BMl. }\end{array}$} \\
\hline
\end{tabular}


Table 4

The association between different risk/protect factors with thyroid nodules

\begin{tabular}{|c|c|c|c|c|c|c|}
\hline \multirow[t]{2}{*}{ Characteristics } & \multicolumn{3}{|c|}{ Univariate logistic regression } & \multicolumn{3}{|c|}{ Multivariate logistic regression } \\
\hline & OR & $95 \% \mathrm{Cl}$ & $P$ value & OR & $95 \% \mathrm{Cl}$ & $P$ value \\
\hline \multicolumn{7}{|l|}{ Age(years) } \\
\hline$\leq 40$ & \multicolumn{3}{|c|}{ reference } & \multicolumn{3}{|c|}{ reference } \\
\hline $40-60$ & 2.566 & $1.806-3.644$ & 0.000 & 2.515 & $1.761-3.593$ & 0.000 \\
\hline$>60$ & 4.675 & $3.141-6.958$ & 0.000 & 4.459 & $2.973-6.687$ & 0.000 \\
\hline \multicolumn{7}{|l|}{ Gender } \\
\hline Male & \multicolumn{3}{|c|}{ reference } & \multicolumn{3}{|c|}{ reference } \\
\hline Female & 1.538 & $1.142-2.070$ & 0.005 & 1.415 & $0.933-2.145$ & 0.102 \\
\hline \multicolumn{7}{|l|}{ Drinker(n,\%) } \\
\hline No & \multicolumn{3}{|c|}{ reference } & \multicolumn{3}{|c|}{ reference } \\
\hline Yes & 0.665 & $0.453-0.977$ & 0.038 & 0.744 & $0.479-1.156$ & 0.189 \\
\hline \multicolumn{7}{|l|}{ Smoker } \\
\hline No & \multicolumn{3}{|c|}{ reference } & \multicolumn{3}{|c|}{ reference } \\
\hline Yes & 0.710 & $0.512-0.983$ & 0.039 & 0.928 & $0.592-1.454$ & 0.745 \\
\hline \multicolumn{7}{|l|}{$\mathrm{BMI}\left(\mathrm{kg} / \mathrm{m}^{2}\right)$} \\
\hline$<25$ & \multicolumn{3}{|c|}{ reference } & \multicolumn{3}{|c|}{ reference } \\
\hline$\geq 25$ & 1.546 & $1.163-2.054$ & 0.003 & 1.390 & $1.030-1.877$ & 0.031 \\
\hline
\end{tabular}

\section{Subgroup analysis about BMI, smoking and drinking}

Table 5 and Table S1 analyzed the correlation between BMI, smoking and drinking as independent risk or protective factors for two thyroid diseases in different subgroups. After adjusting for other covariates, $\mathrm{BMI} \geq 25 \mathrm{~kg} / \mathrm{m} 2$ was significantly associated with subclinical hypothyroidism in people with positive thyroid antibodies $(\mathrm{OR}=2.221,95 \% \mathrm{Cl}: 1.168-4.184, \mathrm{P}=0.015)$ and smokers $(\mathrm{OR}=2.179,95 \% \mathrm{Cl}: 1.041-$ $4.561, P=0.039$ ), Thyroid nodules were significantly associated with thyroid nodules in people over 60 years old $(\mathrm{OR}=2.069,95 \% \mathrm{Cl}: 1.149-3.724, \mathrm{P}=0.015)$ and drinkers $(\mathrm{OR}=3.065,95 \% \mathrm{Cl}: 1.413-6.648, \mathrm{P}$ $=0.005)$. Drinking alcohol has a protective effect on thyroid nodules in smokers $(\mathrm{OR}=0.456,95 \% \mathrm{Cl}$ : 
$0.240-0.865, \mathrm{P}=0.016)$ and people with $\mathrm{BMI} \geq 25 \mathrm{~kg} / \mathrm{m} 2(\mathrm{OR}=0.467,95 \% \mathrm{Cl}: 0.236-0.925, \mathrm{P}=0.029)$. No statistical association was found between smoking and the two thyroid diseases in different subgroups.

Table 5

Associations of subclinical hypothyroidism with BMI and smoker in subgroups stratified by other variables

\begin{tabular}{|c|c|c|c|c|c|c|c|}
\hline \multirow[t]{2}{*}{ Subgroup } & \multirow[t]{2}{*}{$\mathbf{N}$} & \multicolumn{3}{|c|}{$\mathrm{BMI} \geq 25 \mathrm{~kg} / \mathrm{m}^{2}$} & \multicolumn{3}{|c|}{ Smoker } \\
\hline & & OR & $95 \% \mathrm{Cl}$ & $P$ value & OR & $95 \% \mathrm{Cl}$ & $P$ value \\
\hline \multicolumn{8}{|l|}{ Gender $^{a}$} \\
\hline Male & 524 & 1.770 & $0.945-3.315$ & 0.074 & 0.896 & $0.470-1.709$ & 0.739 \\
\hline Female & 755 & 1.464 & $0.990-2.164$ & 0.056 & 1.352 & $0.605-3.023$ & 0.463 \\
\hline \multicolumn{8}{|l|}{ Age(years) ${ }^{b}$} \\
\hline$\leq 40$ & 552 & 1.562 & $0.880-2.773$ & 0.128 & 1.045 & $0.459-2.381$ & 0.916 \\
\hline $40-60$ & 510 & 1.368 & $0.850-2.202$ & 0.197 & 1.293 & $0.574-2.914$ & 0.536 \\
\hline$>60$ & 217 & 2.075 & $0.939-4.585$ & 0.071 & 0.678 & $0.199-2.308$ & 0.535 \\
\hline \multicolumn{8}{|l|}{ Antibody ${ }^{c}$} \\
\hline Antibody- & 1062 & 1.436 & $0.976-2.114$ & 0.066 & 0.763 & $0.419-1.389$ & 0.376 \\
\hline Antibody+ & 217 & 2.221 & $1.168-4.184$ & 0.015 & 2.757 & $0.909-8.359$ & 0.073 \\
\hline \multicolumn{8}{|l|}{ Smoker ${ }^{d}$} \\
\hline No & 902 & 1.443 & $0.994-2.096$ & 0.054 & N/A & & \\
\hline Yes & 377 & 2.179 & $1.041-4.561$ & 0.039 & N/A & & \\
\hline \multicolumn{8}{|c|}{$\mathrm{BMI}\left(\mathrm{kg} / \mathrm{m}^{2}\right)^{\mathrm{e}}$} \\
\hline$<25$ & 792 & N/A & & & 0.833 & $0.382-1.816$ & 0.645 \\
\hline$\geq 25$ & 487 & $\mathrm{~N} / \mathrm{A}$ & & & 1.224 & $0.597-2.512$ & 0.581 \\
\hline \multicolumn{8}{|c|}{ 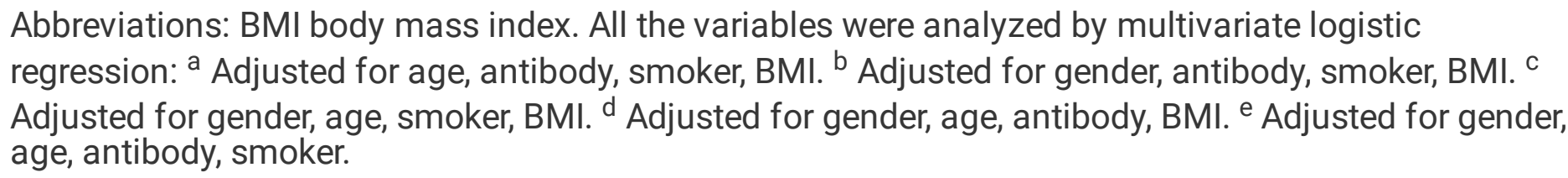 } \\
\hline
\end{tabular}

\section{Discussion}


At present, there are different research results on the relationship between obesity and thyroid disease. Obesity can cause insulin resistance and hyperinsulinemia, making the body inclined to the state of energy reserve [12]. This may inhibit the synthesis and release of thyroid hormones, and studies have shown that insulin itself can also promote abnormal proliferation of thyroid tissue $[15,16]$. In addition, the accumulation of fat in the body and the increase of free fatty acids in circulation may also lead to steatosis and infiltration of the thyroid gland, resulting in changes in thyroid morphology and function [17]. By comparing the thyroxine levels of patients before and after bariatric surgery, several studies found that TSH levels decreased significantly after bariatric surgery, and lasted for a long time without taking L-T4, indicating that subclinical hypothyroidism tends to be improved spontaneously after weight loss [18-20]. Since many weight loss operations are performed by gastrectomy, obesity-mediated subclinical hypothyroidism is more likely to be affected by some intestinal hormones [21]. For example, GLP-1 can improve the activity of deiodinase and promote the synthesis of thyroid hormone, while the secretion of this hormone increases after weight loss [22]. In addition, leptin secreted by adipose tissue has also been shown to affect the regulation of the hypothalamic-pituitary-thyroid axis, thereby inhibiting thyroid hormone release and stimulating TSH secretion [23-25].

In this study, difference and correlation analysis showed that the risk of subclinical hypothyroidism and thyroid nodules in obese patients (BMI $\geq 25 \mathrm{~kg} / \mathrm{m} 2)$ was higher than that in non-obese patients. Other factors associated with obesity and metabolic syndrome, such as waist circumference and blood pressure, however, were only associated with thyroid nodules. Two studies from South Korea on the clinical characters of subclinical hypothyroidism and thyroid nodules also found similar results [26, 27], although the level of $\mathrm{BMI}$ is positively correlated with the level of $\mathrm{TSH}$, and this correlation persists even the TSH level fluctuates slightly within the normal reference range, the presence or absence of metabolic syndrome does not affect the occurrence of subclinical hypothyroidism. It is suggested that metabolic status may have a more significant effect on the occurrence of thyroid nodules than subclinical hypothyroidism. To some extent, this proves that there is no direct correlation between insulin resistance and subclinical hypothyroidism. In addition, a study of women with polycystic ovary syndrome(PCOS) found that other metabolic conditions were associated with TSH levels only in obese PCOS women [28], suggesting that obesity may be a necessary condition for mediating the mechanism of hyperinsulinemia on thyroid gland. In contrast, the relationship between thyroid nodules and metabolic disorders such as impaired glucose tolerance, metabolic syndrome and insulin resistance has been confirmed in a number of observational studies [29-31]. In our study, the high correlation between thyroid nodules and these indexes also suggests that the effect of adverse metabolic status on thyroid may be more emphasis on non-functional and morphological changes, which does not need to be mediated by obesity. This needs to be proved by further pathological results.

Among participants in different age groups, we found that people aged 40-60 had the highest risk of subclinical hypothyroidism. But for thyroid nodules, the older the age, the greater the risk. In elderly patients, the effect of BMI on thyroid nodules is also more obvious. The different effects of age on the two diseases may be due to subtle differences in pathogenesis, the exact mechanism of which is still unclear. However, we speculate that the protective effect of advanced age ( $>60$ years old) on subclinical 
hypothyroidism may be due to the decrease of fat factors such as leptin in the elderly, which can inhibit the secretion of thyroid hormone. In contrast, the occurrence of thyroid nodules is less affected by the regulation of hormones in the body, while the slow local metabolism of the thyroid gland in the elderly leads to the accumulation and proliferation of thyroid tissue, which has a synergistic effect with obesity. In terms of gender, the prevalence of thyroid disease was higher in women than in men, but subgroup analysis did not show that BMI had different effects on men and women. Our findings may be due to a small sample size, but the association between gender, obesity and thyroid disease may be complex. A previous study, also from Tianjin, China, showed that BMI was not associated with the incidence of subclinical hypothyroidism in women, but played a protective role in men [32], which contradicted the results of many previous studies [33-35]. Estrogen may have a unique pathological effect on thyroid gland so that women are susceptible to thyroid disease [36], but it also has a different effect on the distribution and metabolism of human fat than that of men. These two mechanisms make the relationship between obesity and thyroid disease different in different genders, and more in-depth research is needed to prove it.

Thyroid autoantibody levels are increased in patients with subclinical hypothyroidism, but there is no such trend in patients with thyroid nodules. Patients with TPOAb have the highest risk of subclinical hypothyroidism because TPOAb has been shown to play a direct role in thyroid destruction through antibody and complement-mediated cytotoxicity. In the subgroup analysis, BMI was directly associated with the risk of subclinical hypothyroidism only in antibody positive patients. There is often abnormal lymphocyte infiltration in the thyroid tissue of these patients, and studies have shown that obesity itself is also a chronic inflammatory state. In obese patients, there is an increasing trend of cytokines secreted by immune cells as inflammatory markers [37]. By comparing the changes of inflammatory factors in patients with subclinical hypothyroidism after weight loss, Zhu, C et al found that the decreasing trend of pro-inflammatory factors such as IL-6, CRP and TNF- a was positively correlated with the decrease of TSH [20]. This suggests that obesity and Hashimoto's thyroiditis may have a synergistic effect on thyroid tissue damage, making the effect of obesity on thyroid more obvious. Hashimoto's thyroiditis patients with obesity are more likely to develop subclinical or even clinical hypothyroidism than non-obese patients.

Current studies have shown that lifestyles such as smoking and drinking have certain benefits for thyroid disease, but the exact mechanism is unknown. A cohort study of 10 million people in South Korea showed that smokers and drinkers had a reduced risk of thyroid cancer, and the two had a synergistic effect [38]. Other studies have shown that stopping smoking leads to an increased risk of thyroid autoantibodies, which leads to subclinical hypothyroidism [39]. In our study, the effects of smoking and drinking on thyroid disease showed very complex results after multivariate analysis and subgroup analysis. Univariate logistics regression showed that smoking had a certain protective effect on two kinds of thyroid diseases, and the prevalence rate of two kinds of thyroid diseases in smokers was significantly lower than that in non-smokers. However, after adjusting other covariates, the protective effect of smoking was eliminated. In the subgroup analysis, no association between smoking and disease was observed in a subgroup. The history of alcohol addiction only has a protective effect on thyroid nodules, 
especially in smokers and non-obese people, drinking has a significant statistical significance on the reduction of the prevalence of thyroid nodules.

It is worth noting that in the subgroup analysis, smokers were more likely to be affected by BMI-induced subclinical hypothyroidism than non-smokers after matching other factors. Similarly, drinkers are more susceptible to the effects of BMI on thyroid nodules than non-drinkers. This may be due to our small sample size, because there are only 38 patients in the subgroup of smoking with subclinical hypothyroidism and 36 patients with thyroid nodules while drinking alcohol. Considering that the lifestyle of smoking and drinking can also lead to obesity and metabolic disorders, the proportion of obese patients is relatively large. Previous studies have also shown that there is no difference in the effects of obese subclinical hypothyroidism between smokers and non-smokers [40]. However, the independent protective effect of smoking and drinking on thyroid disease seems to contradict the harm caused by obesity, especially the protection of drinking on thyroid nodules may interact with the pathological mechanism of obesity on thyroid disease. Therefore, the future research on the risk of thyroid disease should pay more attention to the people who are obese at the same time of smoking and drinking.

In our study, urinary iodine levels were used as continuous variables and enumerative variables, respectively, but no differences were found between patients with subclinical hypothyroidism and thyroid nodules and non-patients. This shows that iodine nutrition status has no effect on the prevalence of thyroid diseases, and the results are not consistent with the results of the national iodine nutrition survey in China [41]. Although it is considered that the effect of iodine on thyroid is long-term, the cross-sectional difference of small sample size may not be significant. However, it also shows that high iodine diet as a lifestyle has less significant effect on thyroid than obesity, smoking and drinking, and there is no need to deliberately control iodine intake for prevention of subclinical hypothyroidism and thyroid nodules.

Our study has the following limitations. Because it is based on population screening, the sample size of the disease is small. In addition, the study is a cross-sectional study, so it is not possible to determine the causal relationship between risk factors and disease. For the subgroups in this study, larger studies are still needed to confirm the exact relationship between the covariates.

\section{Conclusion}

Obesity is a risk factor for thyroid disease, especially in subclinical hypothyroidism patients with positive thyroid antibodies and in elderly patients with thyroid nodules. Compared with subclinical hypothyroidism, obesity and poor metabolism have a greater impact on the prevalence of thyroid nodules, suggesting that the effect of metabolism on thyroid is more morphological and non-functional. Smoking may be a protective factor for thyroid disease, while drinking is a protective factor for thyroid nodules in obese people. The mechanism needs to be further clarified.

\section{Abbreviations}


WHO: World health organization; BMI: Body mass index; DBP: Diastolic blood pressure; ORs: Odd ratios; SBP: Systolic blood pressure; TNs: Thyroid nodules; SHO: subclinical hypothyroidism; TPOAb: thyroid peroxidase antibody; TgAb: thyroglobulin antibody; TSH: thyroid-stimulating hormone; CRP: C-reactive protein; IL-6: interleukin-6; PCOS: polycystic ovary syndrome; FT3: free triiodothyronine; FT4: free tetraiodothyronine; GLP-1: Glucagon-Like Peptide 1

\section{Declarations}

\section{Acknowledgements}

The authors are grateful to all the organizations and people who participated in the study, the China Medical University and Huazhong University of Science and Technology.

\section{Authors' contributions}

All authors made substantial contributions to the conception and design of this study. XC performed the data analyses and wrote the manuscript; JJW performed the data collection and manuscript preparation. HS contributed to the conception of the study and professional comments on the content.

LY and HYW helped in manuscript preparation.

\section{Funding}

The project was funded by Wuhan Science and Technology Research Program of China (No. 201161038340-02). The funder had no role on the study design, data analysis, interpretation and writing the manuscript in this study.

\section{Availability of data and materials}

The datasets used and/or analysed during the current study are available from the corresponding author on reasonable request.

\section{Ethics approval and consent to participate}

The present study was approved by the Ethics Committee of medical ethics committee of China Medical University (Serial number: IRB[2008]34), the written informed consent was obtained from each participant. All procedures performed in studies involving human participants were in accordance with the ethical standards of the institutional and/or national research committee and with the $1964 \mathrm{Helsinki}$ declaration and its later amendments or comparable ethical standards. 


\section{Consent for publication}

Not applicable.

\section{Competing interests}

The authors declare that they have no competing interests.

\section{References}

1. Cooper DS, Biondi B. Subclinical thyroid disease. Lancet. 2012;379(9821):1142-54.

2. Durante C, Grani G, Lamartina L, Filetti S, Mandel SJ, Cooper DS. The Diagnosis and Management of Thyroid Nodules: A Review. JAMA. 2018;319(9):914-24.

3. Ro K, Yuen AD, Du L, Ro CC, Seger C, Yeh MW, et al. Impact of Hypothyroidism and Heart Failure on Hospitalization Risk. Thyroid. 2018;28(9):1094-100.

4. Pasqualetti G, Pagano G, Rengo G, Ferrara N, Monzani F. Subclinical Hypothyroidism and Cognitive Impairment: Systematic Review and Meta-Analysis. J Clin Endocrinol Metab. 2015;100(11):4240-8.

5. Paschou SA, Vryonidou A, Goulis DG. Thyroid nodules: A guide to assessment, treatment and followup. Maturitas. 2017;96:1-9.

6. Guo H, Sun M, He W, Chen H, Li W, Tang J, et al. The prevalence of thyroid nodules and its relationship with metabolic parameters in a Chinese community-based population aged over 40 years. Endocrine. 2014;45(2):230-5.

7. Peeters RP. Subclinical Hypothyroidism. N Engl J Med. 2017;376(26):2556-65.

8. Kwong N, Medici M, Angell TE, Liu X, Marqusee E, Cibas ES, et al. The Influence of Patient Age on Thyroid Nodule Formation, Multinodularity, and Thyroid Cancer Risk. J Clin Endocrinol Metab. 2015;100(12):4434-40.

9. Lai X, Zhang B, Wang Y, Jiang Y, Li J, Gao L, et al. Adiposity and the risk of thyroid nodules with a high-suspicion sonographic pattern: a large cross-sectional epidemiological study. J Thorac Dis. 2019;11(12):5014-22.

10. Pekgor S, Duran C, Kutlu R, Solak I, Pekgor A, Eryilmaz MA. Visceral Adiposity Index Levels in Patients with Hypothyroidism. J Natl Med Assoc. 2018;110(6):606-13.

11. Wang N, Fang H, Fu C, Huang P, Su M, Jiang F, et al. Associations of adiposity measurements with thyroid nodules in Chinese children living in iodine-sufficient areas: an observational study. BMJ Open. 2017;7(10):e016706.

12. Yang HX, Zhong Y, Lv WH, Zhang F, Yu H. Association of adiposity with thyroid nodules: a crosssectional study of a healthy population in Beijing, China. BMC Endocr Disord. 2019;19(1):102.

13. Mallick UK. The revised American Thyroid Association management guidelines 2009 for patients with differentiated thyroid cancer: an evidence-based risk-adapted approach. Clin Oncol (R Coll 
Radiol). 2010;22(6):472-4.

14. Appropriate body-mass index for Asian populations and its implications for policy and intervention strategies. Lancet. 2004;363(9403):157-63.

15. Kushchayeva YS, Kushchayev SV, Startzell M, Cochran E, Auh S, Dai Y, et al. Thyroid Abnormalities in Patients With Extreme Insulin Resistance Syndromes. J Clin Endocrinol Metab. 2019;104(6):2216-28.

16. Wang K, Yang Y, Wu Y, Chen J, Zhang D, Mao X, et al. The association between insulin resistance and vascularization of thyroid nodules. J Clin Endocrinol Metab. 2015;100(1):184-92.

17. Lee MH, Lee JU, Joung KH, Kim YK, Ryu MJ, Lee SE, et al. Thyroid dysfunction associated with follicular cell steatosis in obese male mice and humans. Endocrinology. 2015;156(3):1181-93.

18. Granzotto PCD, Mesa Junior CO, Strobel R, Radominski R, Graf H, de Carvalho GA. Thyroid function before and after Roux-en-Y gastric bypass: an observational study. Surg Obes Relat Dis. 2020;16(2):261-9.

19. Almunif DS, Bamehriz F, Althuwaini S, Almigbal TH, Batais MA. The Effect of Laparoscopic Sleeve Gastrectomy on Serum Thyroid-Stimulating Hormone Levels in Obese Patients with Overt and Subclinical Hypothyroidism: a 7-Year Retrospective Study. Obes Surg. 2020;30(4):1491-7.

20. Zhu C, Gao J, Mei F, Lu L, Zhou D, Qu S. Reduction in Thyroid-Stimulating Hormone Correlated with Improved Inflammation Markers in Chinese Patients with Morbid Obesity Undergoing Laparoscopic Sleeve Gastrectomy. Obes Surg. 2019;29(12):3954-65.

21. Emami A, Nazem R, Hedayati M. Is association between thyroid hormones and gut peptides, ghrelin and obestatin, able to suggest new regulatory relation between the HPT axis and gut? Regul Pept. 2014;189:17-21.

22. Kohli R, Bradley D, Setchell KD, Eagon JC, Abumrad N, Klein S. Weight loss induced by Roux-en-Y gastric bypass but not laparoscopic adjustable gastric banding increases circulating bile acids. J Clin Endocrinol Metab. 2013;98(4):E708-12.

23. Santini F, Marzullo P, Rotondi M, Ceccarini G, Pagano L, Ippolito S, et al. Mechanisms in endocrinology: the crosstalk between thyroid gland and adipose tissue: signal integration in health and disease. Eur J Endocrinol. 2014;171(4):R137-52.

24. Kalinowski P, Paluszkiewicz R, Wróblewski T, Remiszewski P, Grodzicki M, Bartoszewicz Z, et al. Ghrelin, leptin, and glycemic control after sleeve gastrectomy versus Roux-en-Y gastric bypass-results of a randomized clinical trial. Surg Obes Relat Dis. 2017;13(2):181-8.

25. Kruljac I, Mirošević G, Kirigin LS, Nikolić M, Ljubičić N, Budimir I, et al. Changes in metabolic hormones after bariatric surgery and their predictive impact on weight loss. Clin Endocrinol (Oxf). 2016;85(6):852-60.

26. Lee MK, Kim YM, Sohn SY, Lee JH, Won YJ, Kim SH. Evaluation of the relationship of subclinical hypothyroidism with metabolic syndrome and its components in adolescents: a population-based study. Endocrine. 2019;65(3):608-15.

27. Moon JH, Hyun MK, Lee JY, Shim JI, Kim TH, Choi HS, et al. Prevalence of thyroid nodules and their associated clinical parameters: a large-scale, multicenter-based health checkup study. Korean J 
Intern Med. 2018;33(4):753-62.

28. Tagliaferri V, Romualdi D, Guido M, Mancini A, De Cicco S, Di Florio C, et al. The link between metabolic features and TSH levels in polycystic ovary syndrome is modulated by the body weight: an euglycaemic-hyperinsulinaemic clamp study. Eur J Endocrinol. 2016;175(5):433-41.

29. Ayturk S, Gursoy A, Kut A, Anil C, Nar A, Tutuncu NB. Metabolic syndrome and its components are associated with increased thyroid volume and nodule prevalence in a mild-to-moderate iodinedeficient area. Eur J Endocrinol. 2009;161(4):599-605.

30. Anil C, Akkurt A, Ayturk S, Kut A, Gursoy A. Impaired glucose metabolism is a risk factor for increased thyroid volume and nodule prevalence in a mild-to-moderate iodine deficient area. Metabolism. 2013;62(7):970-5.

31. Liu Y, Lin Z, Sheng C, Zhu Y, Huang Y, Zhong N, et al. The prevalence of thyroid nodules in northwest China and its correlation with metabolic parameters and uric acid. Oncotarget. 2017;8(25):41555-62.

32. Pan Z, Huang C, Meng Z, Zhang W, Li Y, Yu X, et al. THE ASSOCIATION BETWEEN BODY MASS INDEX AND SUBCLINICAL THYROID DYSFUNCTION IN DIFFERENT SEXES OF CHINESE. Endocr Pract. 2019;25(11):1166-75.

33. Kim JY, Jung EJ, Park ST, Jeong SH, Jeong CY, Ju YT, et al. Body size and thyroid nodules in healthy Korean population. J Korean Surg Soc. 2012;82(1):13-7.

34. Jiang L, Du J, Wu W, Fang J, Wang J, Ding J. Sex differences in subclinical hypothyroidism and associations with metabolic risk factors: a health examination-based study in mainland China. BMC Endocr Disord. 2020;20(1):100.

35. Wang B, Song R, He W, Yao Q, Li Q, Jia X, et al. Sex Differences in the Associations of Obesity With Hypothyroidism and Thyroid Autoimmunity Among Chinese Adults. Front Physiol. 2018;9:1397.

36. Lu Y, Li J, Li J. Estrogen and thyroid diseases: an update. Minerva Med. 2016;107(4):239-44.

37. Li Q, Wang Q, Xu W, Ma Y, Wang Q, Eatman D, et al. C-Reactive Protein Causes Adult-Onset Obesity Through Chronic Inflammatory Mechanism. Front Cell Dev Biol. 2020;8:18.

38. Yeo Y, Shin DW, Han KD, Kim D, Kim TH, Chun S, et al. Smoking, alcohol consumption, and the risk of thyroid cancer: a population-based Korean cohort study of 10 million people. Thyroid. 2020.

39. Effraimidis G, Tijssen JG, Wiersinga WM. Discontinuation of smoking increases the risk for developing thyroid peroxidase antibodies and/or thyroglobulin antibodies: a prospective study. J Clin Endocrinol Metab. 2009;94(4):1324-8.

40. Asvold BO, Bjøro T, Vatten LJ. Association of serum TSH with high body mass differs between smokers and never-smokers. J Clin Endocrinol Metab. 2009;94(12):5023-7.

41. Li Y, Teng D, Ba J, Chen B, Du J, He L, et al. Efficacy and Safety of Long-Term Universal Salt Iodization on Thyroid Disorders: Epidemiological Evidence from 31 Provinces of Mainland China. Thyroid. 2020;30(4):568-79.

\section{Figures}




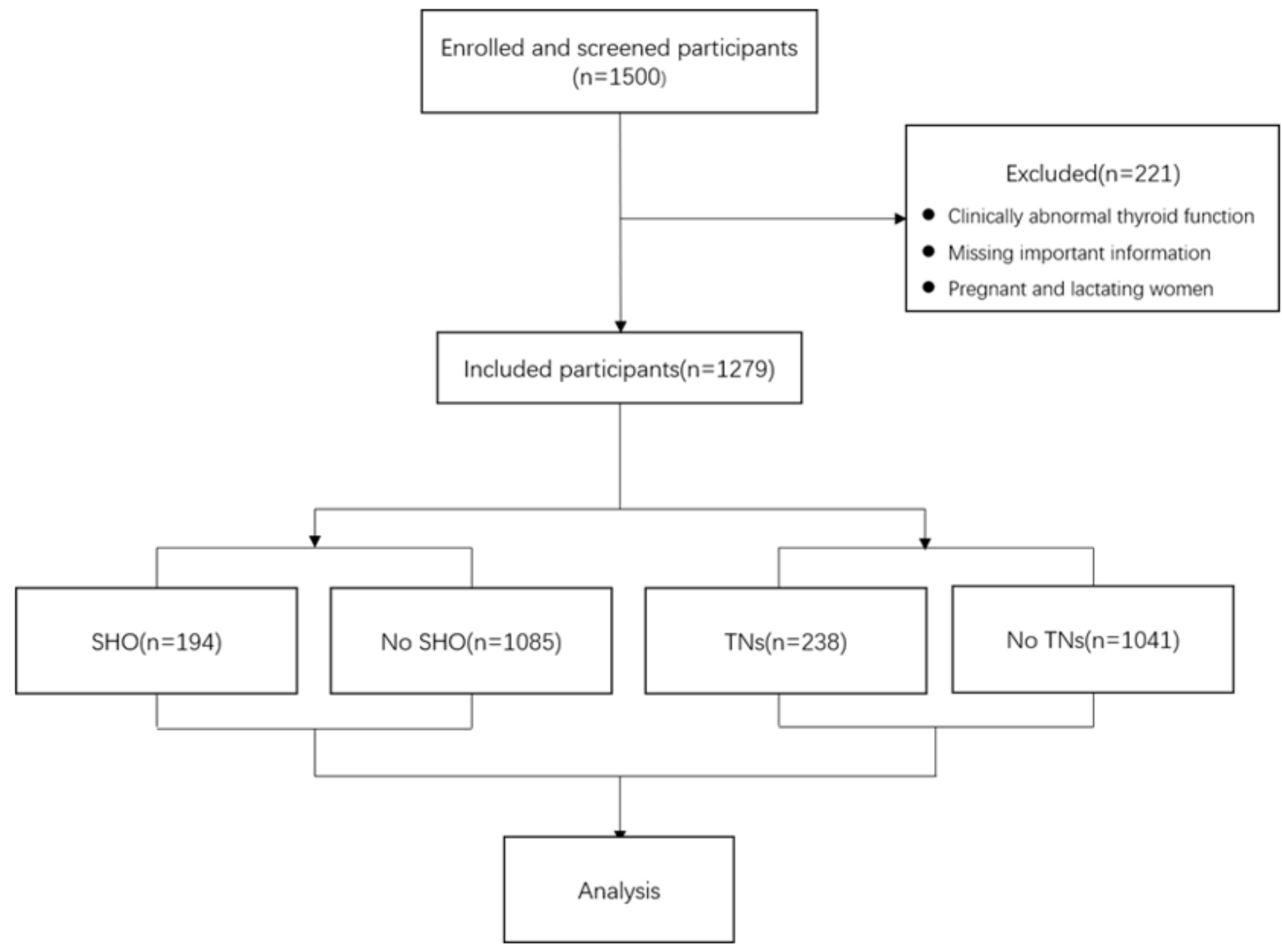

Figure 1

Flow chart of enrollment and grouping, SHO subclinical hypothyroidism, TNs thyroid nodules

\section{Supplementary Files}

This is a list of supplementary files associated with this preprint. Click to download.

- TableS1.xlsx 